\title{
BOUNDEDNESS FOR MULTILINEAR OPERATORS OF PSEUDO-DIFFERENTIAL OPERATORS FOR THE EXTREME CASES
}

\author{
LANZHE LIU
}

Abstract. We prove the boundedness of the multilinear operators associated to the pseudodifferential operator for the extreme cases.

Mathematics subject classification (2010): 42B20, 42B25.

Keywords and phrases: Multilinear operator, pseudo-differential operator, BMO space, Hardy space, Herz space.

\section{REFERENCES}

[1] S. Chanillo And A. Torchinsky, Sharp function and weighted $L^{p}$ estimates for a class of pseudo-differential operators, Ark. Math., 24 (1986), 1-25.

[2] W. G. CHEN AND G. E. Hu, Weak type $\left(H^{1}, L^{1}\right)$ estimate for multilinear singular integral operator, Adv. in Math.(China), 30 (2001), 63-69.

[3] J. Cohen, A sharp estimate for a multilinear singular integral on $R^{n}$, Indiana Univ. Math. J., 30 (1981), 693-702.

[4] J. Cohen And J. Gosselin, On multilinear singular integral operators on $R^{n}$, Studia Math., 72 (1982), 199-223.

[5] J. COHEN AND J. Gosselin, A BMO estimate for multilinear singular integral operators, Illinois J. Math., 30 (1986), 445-465.

[6] R. COIFMAn And Y. Meyer, Au delá des opérateurs pseudo-différentiels, Astérisque, 57 (1978).

[7] R. CoIfman And Y. MEYER, Wavelets, Calderón-Zygmund and multilinear operators, Cambridge Studies in Advanced Math., 48, Cambridge University Press, Cambridge, 1997.

[8] C. FefFERMAn, $L^{p}$ bounds for pseudo-differential operators, Israel J. Math., 14 (1973), $413-417$.

[9] J. GARCIA-CUERVA AND J. L. RuBIO DE FRANCIA, Weighted norm inequalities and related topics, North-Holland Math., 16, Amsterdam, 1985.

[10] E. Harboure, C. Segovia And J. L. Torrea, Boundedness of commutators of fractional and singular integrals for the extreme values of p, Illinois J. Math., 41 (1997), 676-700.

[11] N. Miller, Weighted Sobolev spaces and pseudo-differential operators with smooth symbols, Trans. Amer. Math. Soc., 269 (1982), 91-109.

[12] E. M. STEIn, Harmonic Analysis: real variable methods, orthogonality and oscillatory integrals, Princeton Univ. Press, Princeton NJ, 1993.

[13] C. PÉreZ AND R. TRujillo-GonZAlez, Sharp weighted estimates for multilinear commutators, J. London Math. Soc., 65 (2002), 672-692.

[14] M. Saidani, A. LAhmar-Benbernou And S. Gala, Pseudo-differential operators and commutators in multiplier spaces, African Diaspora J. of Math., 6 (2008), 31-53.

[15] M. E. TAYLOR, Pseudo-differential operators and nonlinear PDE, Birkhauser, Boston, 1991. 